\title{
Agulhas ring formation as a barotropic instability of the retroflection
}

\author{
Wilbert Weijer, ${ }^{1}$ Volodymyr Zharkov, ${ }^{2}$ Doron Nof, ${ }^{3}$ Henk A. Dijkstra, ${ }^{4}$ \\ Wilhelmus P. M. de Ruijter, ${ }^{4}$ Arjen Terwisscha van Scheltinga, ${ }^{5}$ and Fred Wubs ${ }^{6}$ \\ Received 19 August 2013; revised 29 September 2013; accepted 3 October 2013; published 17 October 2013.
}

[1] Agulhas Leakage is an important link in the global ocean circulation, as it transfers a significant volume of relatively warm and salty water from the Indian Ocean to the Atlantic Ocean. The main route of this transfer is through the shedding of large Agulhas rings from the Agulhas retroflection. In this paper we study the dynamics of the ring formation process by analyzing the stability of the Indian/Atlantic supergyre in a reduced gravity model. We show that the ringshedding process results from a barotropic instability of the steady circulation in the Agulhas retroflection region. The destabilizing mode appears to be linked to a Rossby basin mode of the combined South Indian/Atlantic basin, which is localized in the retroflection region by the background flow. Citation: Weijer, W., V. Zharkov, D. Nof, H. A. Dijkstra, W. P. M. de Ruijter, A. Terwisscha van Scheltinga, and F. Wubs (2013), Agulhas ring formation as a barotropic instability of the retroflection, Geophys. Res. Lett., 40, 5435-5438, doi:10.1002/ 2013GL057751.

\section{Introduction}

[2] One of the most fascinating phenomena in the ocean is the retroflection of the Agulhas Current (see de Ruijter et al. [1999] and Beal et al. [2011] for reviews). Flowing southwestward along the east coast of southern Africa, the Agulhas Current overshoots the continent and makes a tight turn back into the South Indian Ocean as the Agulhas Return Current. Occasional occlusions of this loop generate Agulhas rings that subsequently drift westward into the South Atlantic Ocean [e.g., Lutjeharms and Gordon, 1987; Schouten et al., 2000]. This exchange couples the winddriven gyres of the South Indian and Atlantic Oceans into a so-called "supergyre" [de Ruijter, 1982; Speich et al., 2007] and provides a gateway for the upper limb of the global overturning circulation [Gordon, 1985]. In fact, the associated input of warm and salty water into the Atlantic may impact

\footnotetext{
Additional supporting information may be found in the online version of this article.

${ }^{1}$ Los Alamos National Laboratory, New Mexico, USA.

${ }^{2}$ Center for Ocean-Atmospheric Prediction Studies, Tallahassee, Florida, USA.

${ }^{3}$ Florida State University, Tallahassee, Florida, USA.

${ }^{4}$ Institute for Marine and Atmospheric Research Utrecht, Utrecht, Netherlands.

${ }^{5}$ University of Bristol, Bristol, UK.

${ }^{6}$ University of Groningen, Groningen, Netherlands.

Corresponding author: W. Weijer, Los Alamos National Laboratory, CCS-2, MS B214, Los Alamos, NM 87545, USA. (wilbert@lanl.gov)

(C) 2013 The Authors. Geophysical Research Letters published by Wiley on behalf of the American Geophysical Union.

This is an open access article under the terms of the Creative Commons Attribution-NonCommercial-NoDerivs License, which permits use and distribution in any medium, provided the original work is properly cited, the use is non-commercial and no modifications or adaptations are made. 0094-8276/13/10.1002/2013GL057751
}

the strength [Weijer et al., 1999], stability [Weijer et al., 2001], and variability [Biastoch et al., 2008] of the Atlantic Meridional Overturning circulation.

[3] The dynamical reason for the process of ring shedding is still a matter of debate. Nof and Pichevin [1996] analyzed the nonlinear inviscid dynamics of an Agulhas-like current and derived a contradiction ("retroflection paradox") that suggests that a steady retroflection of the Agulhas Current cannot exist. They argue that the regular shedding of these rings provides a net westward force that is essential for sustaining the Agulhas Return Current.

[4] An alternative point of view was put forward by Dijkstra and de Ruijter [2001a] and Dijkstra and de Ruijter [2001b] (hereafter jointly DdR01), who argued that Agulhas rings are instead a result of a barotropic instability of a steady retroflecting state. They found that partially retroflecting steady states $d o$ exist in their reduced gravity shallow water model, and that these states may become unstable to an oscillatory mode. They tentatively identified this mode as a Rossby basin mode in a rectangular basin [Longuet-Higgins, 1964; Pedlosky, 1965], modified by the basin geometry, and destabilized by the background flow. LaCasce and Isachsen [2007] showed that such barotropic instabilities even exist in background states with a non-retroflecting Agulhas Current.

[5] Both views on ring shedding are not mutually exclusive, however, since the retroflection paradox (i) only concerns retroflections in the inviscid state, a limit which is all but impossible to achieve in the numerical context of DdR01 and (ii) only makes a statement about the necessity of rings to sustain a retroflection and not on the dynamics that lead to ring generation. In this context the reader is also referred to van Leeuwen and de Ruijter [2009, 2012] and Nof et al. [2012].

[6] The computational domain of DdR01 only captured a very small environment of the Agulhas Retroflection region. The modes that were found appeared to be strongly constrained by the presence of boundaries. This makes it difficult to assess the robustness and generality of the results in the context of a more realistic basin size. In this paper we extend the work in DdR01 by studying the stability of the South Indian/Atlantic supergyre in a domain of realistic dimensions. We show that the supergyre is destabilized by a mode that has a dominant expression in the Agulhas retroflection region. The spatial and temporal evolution of this mode, the retroflection mode, shows close resemblance to the ring-shedding process, suggesting that this process is related to a barotropic instability of the shear zone in the Agulhas retroflection region.

\section{Model and Methods}

[7] We use a 1.5 layer reduced gravity shallow water model introduced by Dijkstra and Molemaker [1999] and 
a)

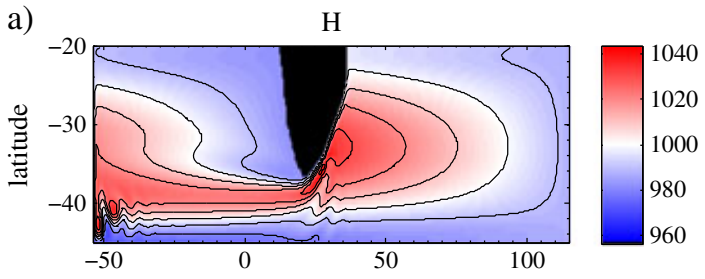

b)

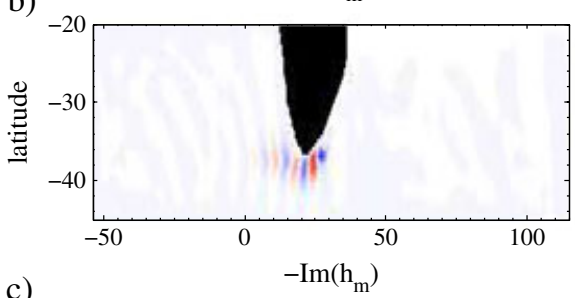

c)

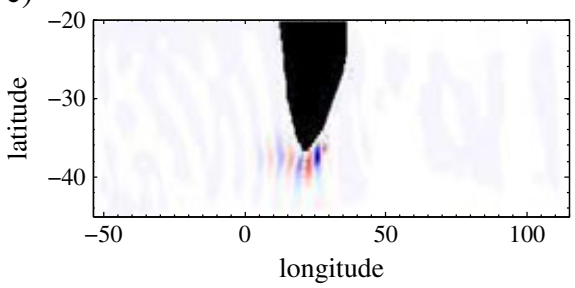

Figure 1. (a) Layer thickness $H$ of our steady standard solution; contour interval is $5 \mathrm{~m}$. (b) Real and (c) minus imaginary patterns of the dominant mode $h_{m}$ that destabilizes this solution. The patterns define an entire oscillatory cycle through the sequence $\mathcal{R}\left(h_{m}\right) \rightarrow-\mathcal{I}\left(h_{m}\right) \rightarrow-\mathcal{R}\left(h_{m}\right) \rightarrow$ $\mathcal{I}\left(h_{m}\right)$. The amplitude of the mode is assumed to be infinitesimally small.

represented by Equation (4) of Schmeits and Dijkstra [2000] (but note that the reduced gravity parameter $g^{\prime}$ replaces the gravitational constant $g$ here). The model hence excludes baroclinic instability. Dynamic variables are zonal $(u)$ and meridional $(v)$ velocity, and layer thickness $h$. We use a Laplacian formulation for eddy viscosity (with coefficient $A_{h}$ ) and include a Rayleigh (interfacial) damping term (with coefficient $r$ ). The equilibrium layer thickness is indicated by $H_{0}$.

[8] We perform three types of analyses [see Dijkstra et al., 2001; Weijer et al., 2003, for more details]: (i) we follow steady states through parameter space using pseudoarclength continuation; (ii) we perform linear stability analyses to determine the least stable normal modes; and (iii) we perform forward time integration using a Backward Euler time-stepping scheme. We use Matrix Renumbering Incomplete LU factorization [Botta and Wubs, 1999] to solve the sparse systems of algebraic equations and the JacobiDavidson QZ method to solve the generalized eigenvalue problems [Sleijpen and van der Vorst, 1996].

[9] Our domain ranges from $-54^{\circ}$ to $115^{\circ}$ longitude and from $-45^{\circ}$ to $-20^{\circ}$ latitude. A continent mass representing southern Africa is based on the $700 \mathrm{~m}$ isobath from ETOPO2 and adjusted manually to smoothen the profile. No efforts are made to include a realistic representation of South America, Madagascar, or Australia. The horizontal resolution is $0.5^{\circ} \times 0.5^{\circ}$; although insufficient to properly resolve the Agulhas Current, it is dictated by the computational requirements and our desire to represent the Indian-Atlantic subtropical gyre in its full extent. Several transient integra-

tions were repeated on a $0.25^{\circ} \times 0.25^{\circ}$ grid to demonstrate robustness of the results with respect to spatial resolution.

[10] The model is forced by a zonal wind stress of the form $\tau_{\phi}(\theta)=\tau_{0} \cos \left(2.7 \pi\left(\theta-\theta_{s}\right)\right)$. It is zonally constant but has a meridional structure that places the latitude of zero wind stress curl at $\theta_{s}=44^{\circ} \mathrm{S}$.

\section{Results}

[11] First, we determine a steady state $(U, V, H)$ of the model for parameter values of $A_{h}=592 \mathrm{~m}^{2} \mathrm{~s}^{-1}, r=7.3$. $10^{-8} \mathrm{~s}^{-1}, H_{0}=1000 \mathrm{~m}, g^{\prime}=0.1 \mathrm{~ms}^{-2}$, and $\tau_{0}=0.11 \mathrm{Nm}^{-2}$. The associated Rossby deformation radius at $40^{\circ} \mathrm{S}$ is about $100 \mathrm{~km}$. The resulting steady state (Figure 1a; referred to as our standard solution) features a realistic Agulhas Current transport of $60 \mathrm{~Sv}$, but Agulhas Leakage (50 Sv) is significantly overestimated; this can be expected given the low resolution of our model and the absence of bathymetry [Matano, 1996; Speich et al., 2006]. The location of the retroflection at $20^{\circ} \mathrm{E}$ compares well with observations, as does the meandering character of the Agulhas Return Current.

[12] A linear stability analysis of this standard solution shows that it is (linearly) unstable with respect to a single (complex-valued) eigenmode $X_{m}=\left(u_{m}, v_{m}, h_{m}\right)$ that we will refer to as the retroflection mode. The oscillation period ( $\left.T_{\text {osc }}\right)$ and growth time scale $\left(T_{\mathrm{gr}}\right)$ are determined by its eigenvalue and are found to be 55 and 69 days, respectively. The spatial pattern of $h_{m}$ is clearly localized in the
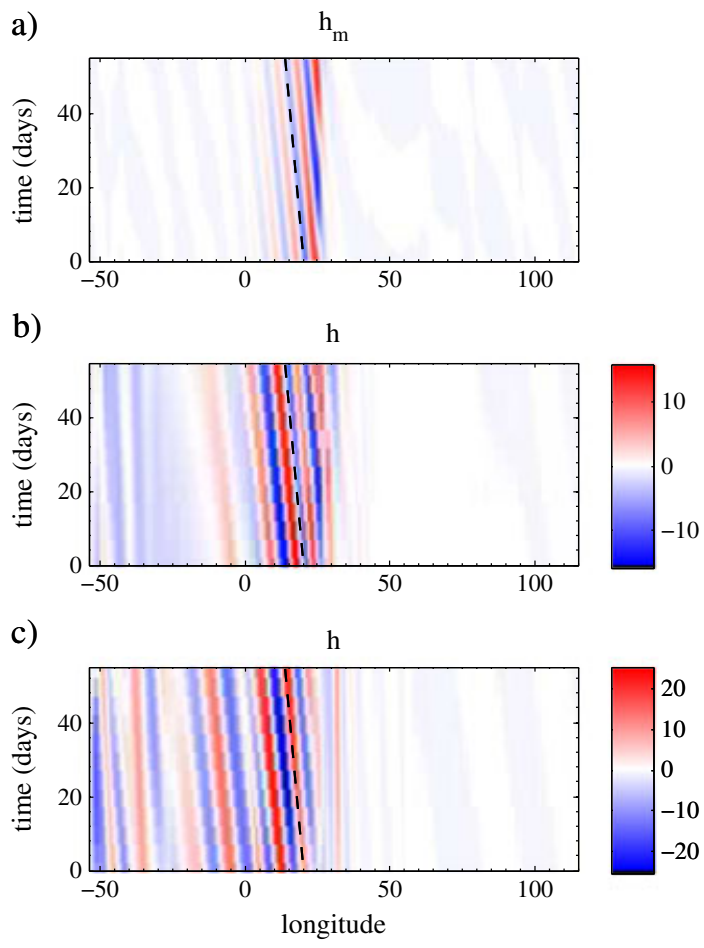

Figure 2. (a) Hovmüller plot of $h_{m}$ at $38^{\circ} \mathrm{S}$ implied by one cycle of the retroflection mode. The amplitude of the mode is assumed to be infinitesimally small. (b) Hovmüller plot of $h$ anomalies (in meters) at $38^{\circ} \mathrm{S}$ for a time integration with horizontal viscosity of $A_{h}=355 \mathrm{~m}^{2} \mathrm{~s}^{-1}$. (c) as in Figure $2 \mathrm{~b}$ but for $A_{h}=118 \mathrm{~m}^{2} \mathrm{~s}^{-1}$ and double spatial resolution $\left(0.25^{\circ}\right)$. Dashed lines indicate a propagation speed of $-0.13 \mathrm{~m} \mathrm{~s}^{-1}$. 
retroflection region (Figures $1 \mathrm{~b}$ and $1 \mathrm{c}$ ). It represents a wave train with zonal wavelength of about $7^{\circ}$ (or $6.1 \cdot 10^{5} \mathrm{~m}$ ) that propagates westward (Figure 2a) with a speed of $-0.13 \mathrm{~m} \mathrm{~s}^{-1}$.

[13] The temporal behavior of the flow is studied by performing time integrations with the same model at subsequently lower values of $A_{h}$. Simulations for $A_{h}=355 \mathrm{~m}^{2} \mathrm{~s}^{-1}$ and for $A_{h}=118 \mathrm{~m}^{2} \mathrm{~s}^{-1}$ (at doubled resolution, $0.25^{\circ}$ ) show the same propagation characteristics as implied by the eigenmode, albeit extending further west with decreasing friction (Figures $2 \mathrm{~b}$ and $2 \mathrm{c}$ ). A sequence of snapshots of the highresolution run (Figure 3) clearly shows (i) the development of ring-like thickness anomalies and anticyclonic circulation in the Agulhas retroflection region; (ii) subsequent westward propagation into the South Atlantic Ocean; and (iii) a characteristic period of about 2 months [see also LaCasce and Isachsen, 2007, Figure 6]. Although computational constraints prevent us from reaching a parameter regime where these anomalies are truly detached and highly nonlinear, it is clear that the characteristics displayed here are fully consistent with the process of Agulhas Ring formation and shedding, as inferred from observations [e.g., Schouten et al., 2000].

[14] As shown in supplementary information, the mean zonal velocity at $25^{\circ} \mathrm{E}$ of our standard solution displays a strong shear between the westward Agulhas Current and the eastward Agulhas Return Current to the south (Figure S1a). Consequently, the gradient of the potential vorticity $\beta_{0}-U^{\prime \prime}$ (where $\beta_{0}$ is the gradient of planetary vorticity) undergoes a zero crossing, which is a necessary condition for barotropic instability [e.g., Kuo, 1949]. The maximum variance of thickness anomalies associated with the retroflection mode is indeed collocated with this zero crossing. Hence, we conclude that the mode results from a barotropic instability of

a)

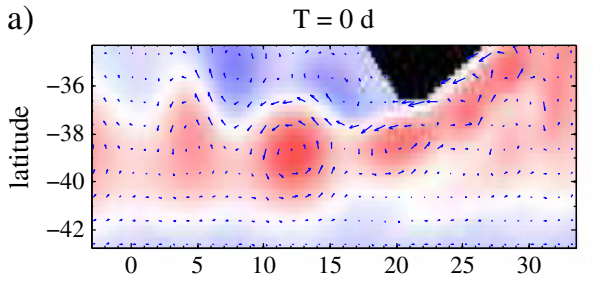

b)

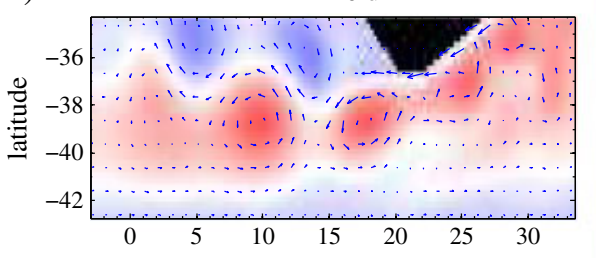

c)

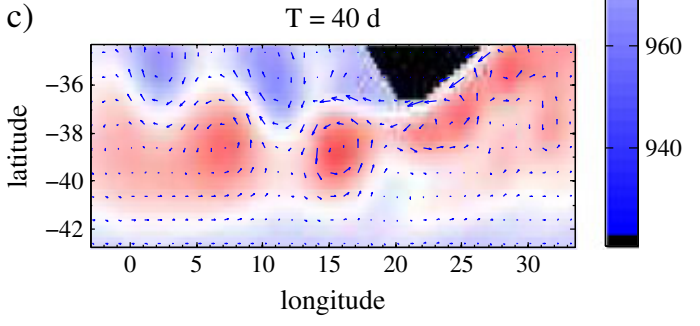

Figure 3. Three snapshots of $h$ (shading) and velocity (vectors; plotted every 4th grid point), 20 days apart in the Agulhas region for the time integration with double spatial resolution $\left(0.25^{\circ}\right)$ and viscosity of $A_{h}=118 \mathrm{~m}^{2} \mathrm{~s}^{-1}$.
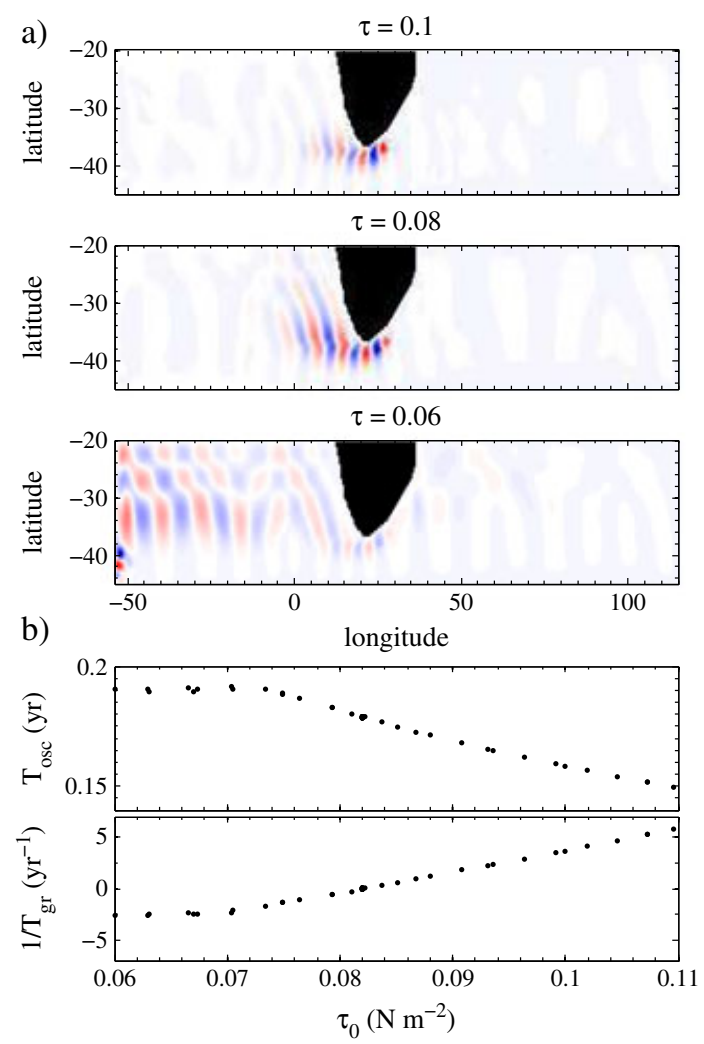

Figure 4. (a) Retroflection mode $\left(\mathcal{R}\left(h_{m}\right)\right)$ for three values of the wind stress amplitude $\tau_{0}$. (b) Oscillation period ( $T_{\text {osc }}$; top) and growth rate $\left(1 / T_{\text {gr }}\right.$; bottom) of the retroflection mode as a function of the wind stress amplitude $\tau_{0}$.

the mean flow in the retroflection region. Indeed, the zonal length scale of the instability is consistent with the least stable mode of a narrow shear zone, following the analysis of Talley [1983] (as shown in Figure S1b).

[15] To determine the spectral origin of the retroflection mode, we attempted to link it to a mode of the unforced basin. To that end, we performed a parameter continuation of the background state by reducing the wind stress $\tau_{0}$. For each steady state, we tried to identify the retroflection mode by calculating the eigenvalue closest to its previously determined value. The retroflection mode could not be unambiguously followed below $\tau_{0}=0.06 \mathrm{Nm}^{-2}$, as apparently the spectrum of the basin modes is too dense for our method to yield robust results. The growth rate $1 / T_{\mathrm{gr}}$ determined through this process (Figure $4 \mathrm{~b}$ ) crosses zero at $\tau_{0}=$ $0.08 \mathrm{Nm}^{-2}$, indicating the presence of a Hopf bifurcation. Both the growth rate and oscillation period display a kink at a value of $\tau_{0}=0.07 \mathrm{Nm}^{-2}$, which seems to be associated with the transition from a localized (e.g., $\tau_{0}=0.08 \mathrm{Nm}^{-2}$ in Figure $4 \mathrm{a})$ to a basin-wide $\left(\tau_{0}=0.06 \mathrm{Nm}^{-2}\right)$ pattern. We interpret this global pattern as a (damped) Rossby basin mode of the coupled South Indian/Atlantic Ocean.

\section{Summary and Discussion}

[16] The results presented here indicate that the Agulhas ring-shedding process is related to a barotropic instability of the South Indian/Atlantic supergyre, in particular, the shear zone between the Agulhas Current and the Agulhas Return Current in the retroflection region. The connection between a 
growing normal mode (Figure 1) and weakly nonlinear transient anomalies (Figure 3) was explicitly demonstrated here; the transition toward fully nonlinear and self-propagating rings is implied by the resemblance with the Agulhas ringshedding process as seen in observations. In particular, the frequency of this mode (6.6 per year) compares well with the observed ring-shedding frequency of 4-6 per year [Schouten et al., 2000].

[17] In addition, we have established a connection between the retroflection mode and a Rossby basin mode of the South Indian/Atlantic Basin. Indeed, the theory of barotropic instability is closely linked to Rossby wave dynamics [e.g., Talley, 1983]. Although local flow conditions determine a preferred length scale of the instability, the modal character is established through association with a basin mode of that approximate wave length. In other words, the barotropic instability localizes the pattern of a global basin mode in the Agulhas retroflection region.

[18] Our standard solution shows only a weak retroflection, but it is the shear zone, not the retroflection per se, that is critical for the instability to develop [LaCasce and Isachsen, 2007]. Steady states with a more pronounced retroflection, obtained by unrealistically shifting the wind profile further north, still robustly feature the retroflection mode. However, other modes now are more unstable (for instance, an instability of the upstream Agulhas Current), making interpretation of the transient integrations less straightforward.

[19] The conclusion presented here is consistent with DdR01 and with the results of Chassignet and Boudra [1988], who studied Agulhas ring formation in a multilayer isopycnic model. In their experiment with low Rossby number, ring formation in the Agulhas retroflection region appeared to be related to the propagation of a basin-scale Rossby basin mode in the lower layer. They found that for this simulation ring formation was dominantly related to a transfer from mean to eddy kinetic energy, pointing at barotropic instability. Energy transfers in additional simulations at higher Rossby numbers suggested the importance of mixed barotropic/baroclinic instabilities, a process that is not captured by our model. In conclusion, while baroclinic effects may come into play in a fully stratified setting, the barotropic instability mechanism is at the core of the Agulhas ring-shedding process.

[20] Acknowledgments. This research was supported by the Institute for Geophysics and Planetary Physics at the Los Alamos National Laboratory and the Regional and Global Climate Modeling Program of the U.S. Department of Energy Office of Science. Los Alamos National Laboratory is operated by the Los Alamos National Security, LLC for the National Nuclear Security Administration of the U.S. Department of Energy under contract DE-AC52-06NA25396. H.D. acknowledges support from the COMPLEXITY project PreKurs, which was funded by the Netherlands Organization for Scientific Research. We thank Joe LaCasce and an anonymous reviewer for their constructive comments.

[21] The Editor thanks two anonymous reviewers for their assistance in evaluating this paper.

\section{References}

Beal, L. M., W. P. M. de Ruijter, A. Biastoch, R. Zahn, and members of SCOR/WCRP/IAPSO Working Group 136 (2011), On the role of the Agulhas system in global climate, Nature, 472, 429-436.

Biastoch, A., C. Böning, and J. Lutjeharms (2008), Agulhas leakage dynamics affects decadal variability in Atlantic overturning circulation, Nature, 456(7221), 489-492.
Botta, E. F. F., and F. W. Wubs (1999), MRILU: An effective algebraic multi-level ILU-preconditioner for sparse matrices, SIAM J. Matrix Anal. Appl., 20, 1007-1026.

Chassignet, E. P., and D. Boudra (1988), Dynamics of the Agulhas Retroflection and ring formation in a numerical model: II. Energetics and ring formation, J. Phys. Oceanogr., 18, 304-319.

de Ruijter, W. (1982), Asymptotic analysis of the Agulhas and Brazil current systems, J. Phys. Oceanogr., 12, 361-373.

de Ruijter, W. P. M., A. Biastoch, S. S. Drijfhout, J. R. E. Lutjeharms, R. P. Matano, T. Pichevin, P. J. van Leeuwen, and W. Weijer (1999), Indian-Atlantic interocean exchange: Dynamics, estimation and impact, J. Geophys. Res., 104, 20,885-20,910.

Dijkstra, H. A., and W. P. M. de Ruijter (2001a), Barotropic instabilities of the Agulhas Current system and their relation to ring formation, J. Mar. Res., 59, 517-533.

Dijkstra, H. A., and W. P. M. de Ruijter (2001b), On the physics of the Agulhas current: Steady retroflection regimes, J. Phys. Oceanogr., 31, 2971-2985.

Dijkstra, H. A., and M. J. Molemaker (1999), Imperfections of the NorthAtlantic wind-driven ocean circulation: Continental geometry and wind stress shape, J. Mar. Res., 57, 1-28.

Dijkstra, H. A., H. Öksüzŏglu, F. W. Wubs, and E. F. F. Botta (2001), A fully implicit model of the three-dimensional thermohaline ocean circulation, J. Comput. Phys., 173, 685-715.

Gordon, A. L. (1985), Indian-Atlantic transfer of thermocline water at the Agulhas Retroflection, Science, 227, 1030-1033.

Kuo, H. L. (1949), Dynamic instability of two-dimensional nondivergent flow in a barotropic atmosphere, J. Meteorol., 6, 105-122.

LaCasce, J. H., and P. E. Isachsen (2007), On Sverdrup discontinuities and vortices in the Southwest Indian Ocean, J. Phys. Oceanogr., 37, 2940-2950

Longuet-Higgins, M. S. (1964), Planetary waves on a rotating sphere, Proc. R. Soc. London, Ser. A, 279, 446-473.

Lutjeharms, J. R. E., and A. L. Gordon (1987), Shedding of an Agulhas ring observed at sea, Nature, 325, 138-140.

Matano, R. P. (1996), A numerical study of the Agulhas retroflection: The role of bottom topography, J. Phys. Oceanogr., 26, 2267-2279.

Nof, D., and T. Pichevin (1996), The retroflection paradox, J. Phys. Oceanogr., 26, 2344-2358.

Nof, D., V. Zharkov, W. Arruda, T. Pichevin, S. Van Gorder, and N. Paldor (2012), Comments on "On the steadiness of separating meandering currents", J. Phys. Oceanogr., 42(8), 1366-1370.

Pedlosky, J. (1965), A study of the time-dependent ocean circulation, J. Atmos. Sci., 22, 267-272.

Schmeits, M. J., and H. A. Dijkstra (2000), Physics of the 9-month variability in the Gulf Stream region: Combining data and dynamical systems analysis, J. Phys. Oceanogr., 30, 1967-1987.

Schouten, M. W., W. P. M. de Ruijter, P. J. van Leeuwen, and J. R. E. Lutjeharms (2000), Translation, decay and splitting of Agulhas rings in the southeastern Atlantic Ocean, J. Geophys. Res., 105, 21,913-21,925.

Sleijpen, G. L. G., and H. A. van der Vorst (1996), A Jacobi-Davidson iteration method for linear eigenvalue problems, SIAM J. Matrix Anal. Appl., 17, 410-425.

Speich, S., J. R. E. Lutjeharms, P. Penven, and B. Blanke (2006), Role of bathymetry in Agulhas Current configuration and behaviour, Geophys. Res. Lett., 33, L23611, doi:10.1029/2006GL027157.

Speich, S., B. Blanke, and W. Cai (2007), Atlantic meridional overturning circulation and the Southern Hemisphere supergyre, Geophys. Res. Lett. 34, L23614, doi:10.1029/2007GL031583.

Talley, L. D. (1983), Radiating barotropic instability, J. Phys. Oceanogr, 13,972-987.

van Leeuwen, P. J., and W. P. M. de Ruijter (2009), On the steadiness of separating meandering currents, J. Phys. Oceanogr., 39(2), 437-448.

van Leeuwen, P. J., and W. P. M. de Ruijter (2012), Reply to "Comments on 'On the steadiness of separating meandering currents"', J. Phys. Oceanogr., 42(8), 1371-1374.

Weijer, W., W. P. M. de Ruijter, H. A. Dijkstra, and P. J. van Leeuwen (1999), Impact of interbasin exchange on the Atlantic overturning circulation, J. Phys. Oceanogr., 29, 2266-2284.

Weijer, W., W. de Ruijter, and H. A. Dijkstra (2001), Stability of the Atlantic overturning circulation: Competition between Bering Street freshwater flux and Agulhas heat and salt sources, J. Phys. Oceanogr., 31, 2385-2402.

Weijer, W., H. A. Dijkstra, H. Öksüzoğlu, F. W. Wubs, and A. C. de Niet (2003), A fully-implicit model of the global ocean circulation, J. Comput. Phys., 192, 452-470. 